LA GRANJA:

REVISTA DE

CIENCIAS DE LA VIDA

pISSN:1390-3799; eISSN:1390-8596

http:/ / doi.org/10.17163/lgr.n27.2018.10
Artículo científico / Scientific paper

DESARRollo RURAL SOSTENIBLE

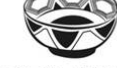

ABYA UNIVERIDAD

YALA PALLIECNICA

\title{
GESTIÓN DE CALIDAD DE LECHE DE PEQUEÑOS Y MEDIANOS GANADEROS DE CENTROS DE ACOPIO Y QUESERÍAS ARTESANALES, PARA LA MEJORA CONTINUA. CASO DE ESTUDIO: CARCHI, ECUADOR
}

\author{
MILK QUALITY MANAGEMENT OF SMALL AND MEDIUM CATTLE RANCHERS \\ OF COLLECTION CENTERS AND ARTISAN CHEESE FACTORIES, FOR \\ CONTINUOUS IMPROVEMENT. CASE STUDY: CARCHI, ECUADOR
} Eloy Guillermo De la Cruz ${ }^{1}$, Paola Simbaña Díaz ${ }^{2}$, Nancy Bonifaz ${ }^{3}$

${ }^{1 *}$ Egresado de la maestría en Economía y administración Agrícola, ESPOCH, Riobamba Ecuador.

${ }^{2}$ Laboratorio de Calidad de leche de la Universidad Politécnica Salesiana, Centro de apoyo Cayambe: Av. Natalia Jarrín y 9 de Octubre Telf. (593-2) 3962885, Ecuador.

${ }^{3}$ Grupo de investigación NUNKUI WAKAN, Universidad Politécnica Salesiana, Campus El Girón: Isabel la Católica N. 23-52 y Madrid.

*Autor para correspondencia: ede@ups.edu.ec; psimbana@ups.edu.ec

\section{Resumen}

El objetivo de esta investigación fue analizar el seguimiento de las buenas prácticas pecuarias de pequeños y medianos productores de leche de la provincia del Carchi, con un proyecto de vinculación bajo convenio interinstitucional entre la Universidad Politécnica Salesiana, Fundación Alpina y el Gobierno Autónomo Descentralizado Provincial del Carchi (GADPC). Se realizó dos muestreos a 630 unidades productivas para determinar la calidad higiénica, sanitaria y físico- química de la leche. Con los resultados de la primera fase se realizó una intervención técnica a los productores mediante visitas de campo, charlas y asesoramiento técnico para el diagnóstico de la mastitis y calidad integral de la leche. En la siguiente fase del proyecto se procedió a realizar la segunda toma de muestras donde se aplicaron las pruebas de laboratorio como $\mathrm{pH}$, crioscopía, lacto fermentación y reductasa. Los resultados más relevantes del estudio fueron; en cuanto a calidad composicional más del $90 \%$ de los productores cumplen la norma NTE INEN 9 para leche cruda; se observó también que el $6.3 \%$ de los ganaderos mejoraron en la calidad higiénica con conteos bacterianos $<600.000 \mathrm{IBC} / \mathrm{ml}$; en la calidad sanitaria no hubo una mejora en la reducción del contenidos de células somáticas.

Palabras claves: leche bovina, células somáticas, microorganismos, lacto fermentación, crioscopia. 


\begin{abstract}
The objective of this research was to analyze the monitoring of good livestock practices of small and medium milk producers in the province of Carchi, with a entailment project under an inter-institutional agreement between the Salesian Polytechnic University, the Alpina Foundation and the Provincial Autonomous Decentralized Government of the Carchi (GADPC). Two samplings were carried out at 630 productive units to determine the hygienic, sanitary and physico-chemical quality of the milk. With the results of the first phase, a technical intervention was made to the farmers through field visits, lectures and technical advice for the diagnosis of mastitis and integral quality of the milk. In the next phase of the project, the second sampling was carried out where laboratory tests were applied such as $\mathrm{pH}$, cryoscopy, lacto fermentation and reductase. The most relevant results of the study were; in terms of compositional quality, more than $90 \%$ of the producers comply with the NTE INEN 9 standard for raw milk; it was also observed that $6.3 \%$ of the farmers improved the hygienic quality with bacterial counts $<600,000 \mathrm{IBC} / \mathrm{ml}$; in sanitary quality there was no improvement in the reduction of somatic cell contents.

Keywords: bovine milk, somatic cells, microorganisms, lacto fermentation, cryoscopy.

Forma sugerida de citar: De la Cruz, E. G., Simbaña Diaz, P., Bonifaz, N.. 2018. Gestión de calidad de leche de pequeños y medianos ganaderos de centros de acopio y queserías artesanales, para la mejora continua. Caso de estudio: Carchi, Ecuador. La Granja: Revista de Ciencias de la Vida. Vol. 27(1):124-136. http://doi.org/10.17163/lgr.n27.2018.10.
\end{abstract}




\section{Introducción}

La leche cruda de microempresas artesanales e industriales utilizadas para la elaboración de productos lácteos, es una mezcla muy variada de estructuras químicas y microorganismos, que hace difícil tener un producto de características constantes, por la variabilidad cultural y tecnológica utilizada en la producción de leche bovina de los campesinos y mestizos asentado en el callejón interandino del Ecuador (Villegas de Gante y Santos Moreno, 2011).

La inocuidad de los alimentos es la parte más importante de la salud pública, esto significa producir o mantener la calidad sanitaria, higiénica y nutricional de los productos, libres de microorganismos patógenos que puedan causar daño al consumidor. Las bacterias causantes de la contaminación pueden estar en; el interior del pezón, estiércol, materiales y equipos de ordeño, aire, personal, el animal, agua, si esta no es tratada adecuadamente (Buxadé Carbó, 2002).

La contaminación con microorganismos comunes, no causan enfermedades a los consumidores, pero estos pueden alterar los componentes de la leche y traer consigo el deterioro de las características propias de los productos elaborados restándole calidad y valor comercial (Villegas de Gante y Santos Moreno, 2011).

Estandarizar la producción de la materia prima con calidad se convierte en una necesidad importante actualmente, para lograr producir productos lácteos de calidad y poder comercializar a nivel nacional con toda seguridad y poder avanzar hacia los mercados internacionales que por cierto tienen un nivel tecnológico de alta de exigencia.

Calidad de leche, entendidos definen como "Aquel producto que cumpla consistentemente con las expectativas nutricionales, sanitarias y organolépticas del consumidor cuya composición justifique lo que se está pagando por ella", es decir el consumidor paga el cumplimiento de las características de la cadena de producción láctea, como es el acatamiento de las especificaciones que exige la planta procesadora (primer "consumidor"), quien a su vez, debe cumplir con los requerimientos que exigen los supermercados (segundo "consumidor"), todo esto para satisfacer las necesidades del consumidor final.

Así, desde el campo hasta la mesa, la calidad de la leche concierne a lecheros, veterinarios, plantas procesadoras, supermercados, autoridades y por supuesto, al consumidor final (CANILEC, 2011).

En un estudio de diagnóstico realizado anteriormente, mediante un convenio interinstitucional entre la Universidad Politécnica Salesiana (UPS), Universidad Politécnica estatal del Carchi (UPEC), Fundación Alpina y el Gobierno Autónomo Descentralizado Provincial del Carchi (GADPC), se evidenció las deficientes prácticas pecuarias repercutiendo en la calidad de la materia prima en los pequeños y medianos productores de la provincia del Carchi (Chuquín Yépez, Aquino Ruíz y De la Cruz González, 2016).

El monitoreo constante de la calidad de la materia prima es primordial $(\mathrm{FAO}, 2017)$ donde el productor y el laboratorio de control, deben ser los principales protagonistas del desarrollo de la cadena láctea en el país. Los centros de acopio y queserías artesanales no están exentas del monitoreo de la calidad de su producto, al contrario por la diversidad cultural en la producción se hace necesario esta actividad, para intentar mejorar y mantener un estándar de calidad.

Por lo expuesto anteriormente, se hace difícil mantener una estandarización en la elaboración de productos lácteos, consecuentemente trayendo consigo una serie de problemas en la industrialización. Antes se debe proponer estandarizar la producción primaria de los pequeños y medianos productores para lograr productos reiterativos en la calidad de la materia prima cumpliendo las normas ecuatorianas, y lo más importante manteniendo la salud de los consumidores que para el caso de Ecuador su objetivo está enfocado en la etapa escolar.

Esta investigación tuvo como objetivo evaluar las buenas prácticas pecuarias con el fin de mejorar la calidad de la leche cruda como materia prima, luego de una intervención técnica, para establecer una cultura de monitoreo, mantener un estándar de calidad y de esta forma garantizar la inocuidad del producto final.

Una materia prima de calidad debe reunir todos los componentes y atributos, físico química (composición), higiénica (microorganismo), sanitaria (enfermedades de las vacas e infecciones de la glándula mamaria) sumado estas cualidades se podrá obtener una "calidad integral" como menciona Villegas de Gante y Santos Moreno (2011), y de esta forma la pequeña y mediana industria obtenga materia prima para elaborados de alta calidad tecnológica (Bacilio, 2016). 


\section{Materiales y Métodos}

\subsection{Ubicación del área de estudio}

La provincia del Carchi está ubicada al norte del callejón interandino entre los paralelos $1^{\circ} 12^{\prime} 43^{\prime \prime}$ y $0^{\circ} 21^{\prime} 50^{\prime \prime}$ de Latitud Norte y entre los meridianos $77^{\circ} 31^{\prime} 36^{\prime \prime}$ y $78^{\circ} 33^{\prime} 12^{\prime \prime}$ de Longitud Occidental. El relieve del terreno es irregular y montañoso. Limita al norte con los ríos Carchi y San Juan en la frontera con Colombia, al sur con la provincia de Imbabura, al este con la provincia de Sucumbíos, y a occidente con la de Esmeraldas. Su pisos climáticos se encuentra desde los 1.200 m.s.n.m., hasta los 4.768 m.s.n.m., y con temperaturas que oscilan entre 0 hasta los $27^{\circ} \mathrm{C}$ en las zonas fronterizas con esmeraldas. Está dividida en seis cantones incluida la capital; Bolívar, Espejo, Mira, Montufar, San Pedro de Huaca, Tulcán (GADPC, 2016).

\subsection{Población en estudio}

El presente estudio se desarrolló en la primera fase con un total de 709 pequeños y medianos productores de leche, agremiados en 16 centros de acopio 4 queseras artesanales, 3 centros de acopio privados y el Centro Agrícola de Tulcán, correspondientes a 5 cantones de la provincia del Carchi, territorialmente distribuidos así: cantón Tulcán 5 asociaciones, 1 Centro Agrícola; cantón Huaca 3 asociaciones; cantón Montufar 4 asociaciones, 3 centros de acopio, 2 queseras artesanales; cantón Espejo 2 asociaciones, 1 quesera artesanal; cantón Mira 1 asociación, 1 quesera artesanal.

En el desarrollo del estudio, en la segunda fase se retiraron 2 centros de acopio privados y una asociación por problemas socio-organizativos, finalizando con 15 centros de acopio asociados, 1 centro de acopio privado, 4 queseras artesanales, sumándose en reemplazo el Centro Agrícola de Tulcán.

Por lo tanto el análisis se realizó en base a los centros que finalizaron el estudio con la segunda toma de 630 muestras.

\subsection{Toma de muestras}

Para la realización de esta investigación se contó con médicos Veterinarios Zootecnistas de la fundación Alpina y el apoyo técnico del GADPC conformado por; la Dirección del departamento de desarrollo económico, dos Médicos Veterinarios Zootecnistas, un Ing. Zootecnista y un promotor para la movilización las dos instituciones contribuyeron con; tres clínicas veterinarias móviles del GADPC y una camioneta de la fundación Alpina. Los análisis fueron realizados en el Laboratorio de calidad de leche de la UPS., ubicado en el centro de apoyo Cayambe.

Se realizaron dos tomas de muestras; la primera como un diagnóstico inicial y una segunda para la evaluación de la asistencia técnica brindada por las clínicas veterinarias móviles del GADPC a los productores con problemas higiénico - sanitario. La toma de muestras estuvo a cargo del personal técnico del GADPC, y técnicos otorgados por fundación Alpina, previamente capacitados por el Laboratorio de Calidad de Leche (LCL) de la Universidad Politécnica Salesiana (UPS), siguiendo el protocolo en base a norma NTE INEN-ISO 707 (2014), las muestras fueron tomadas en el ordeño de la mañana, para microbiología se tomó asepticamente un frasco de $40 \mathrm{ml}$ y se agregó 4 gotas de conservante azidiol (azida de sodio), y se almacenó en un refrigerador con hielos para mantener la cadena de frío hasta el laboratorio. Para el análisis físico químico se tomó un frasco de $40 \mathrm{ml}$ y se agregó una pastilla de conservante bronopol y se almacenó en un cooler con hielos hasta el transporte al LCL. Las muestras para crioscopia, Ph, lactofermentación se tomó en frascos asépticos de $100 \mathrm{ml}$ la cantidad de $80 \mathrm{ml}$ de muestra sin conservante y asegurando la cadena de frío de 4-6 ${ }^{\circ} \mathrm{C}$; en el caso de la prueba CMT no se tomó muetras se realizó directamente en la recepción utilizando una jeringa, tomando la proporción de dos $\mathrm{ml}$ de muestra y $2 \mathrm{ml}$ del reactivo CMT (comercial), y al pie de la vaca usando una paleta para CMT siguiendo la técnica respectiva.

Se tomó una muestra por productor, en el caso de productores con más de dos barriles se tomó en una jarra de forma proporcional de cada barril para luego tomar una sub muestra. Las muestras sin conservante se analizaron en el lapso de una hora, en el caso de la muestras con conservantes se almacenaron en refrigeracion a 4 a $6{ }^{\circ} \mathrm{C}$ y se ingresaron antes de las 48 horas de tomadas al LCL para su análisis, éstas fueron analizadas en el transcurso de 12 horas de llegadas.

\subsection{Primera fase}

En esta fase se realizó un diagnóstico global de la calidad higiénica, sanitaria y físico química (composicional), en la UPS. La prueba de estabilidad pro- 
teica, potencial óxido reducción; y la sanitaria CMT en la recepción en los centros de acopio. Se clasificó a los productores según los resultados de laboratorio, los superiores a $500.000 \mathrm{cs} / \mathrm{ml}$ que indican problemas sanitarios (mastitis); los conteos bacterianos (CBT) superior a $600.000 / \mathrm{ml}$, indicando problemas higiénicos (MAGAP, 2013).

Una vez realizado el diagnóstico en la primera toma de muestras (\%) se procedió a realizar la asistencia técnica con los profesionales otorgados por el GADPC, para luego realizar una segunda toma de muestras (\%)y analizar su avance.

\subsection{Segunda fase}

En esta fase se puso en marcha la intervención de las clínicas móviles a los productores con problemas higiénicos, sanitarios y físico químicos. En el caso de problemas sanitarios mayores a $500.000 \mathrm{cs} / \mathrm{ml}$, se realizó un diagnóstico individual mediante CMT a un total de 1094 bovinos productores de leche perteneciente a los pequeños y medianos productores de los centros de acopio y de las queseras. También se realizó ésta prueba a la leche fresca que se recibe en los tanques de enfriamiento con el fin de monitorear su avance en la calidad sanitaria. Para el caso de los problemas higiénicos se realizó capacitaciones sobre "Calidad higiénica y sanitaria de la leche"; manejo de Antibióticos y adulterantes para el caso de crioscopía, otorgados por docentes de la UPS. En esta fase también se realizó las pruebas de estabilidad proteica (Prueba de alcohol), al momento de la recolección, potencial óxido reducción, crioscopía y lacto fermentación luego de la recepción. La crioscopía se consideró como positivo $(+)$ los resultados menores a $-530 \mathrm{mH}^{\circ}$ y negativo (-) los resultados mayores o iguales a $-530 \mathrm{mH}^{\circ}$ (NTE INEN 9, 2015).

\subsection{Principio de los ensayos}

Conteo Total de Bacterias (TBC o IBC siglas en inglés), su principio es citometría de flujo, estandarizado bajo la normas ISO16297- IDF 161: 2013. El Conteo de Células Somáticas (CCS), su principio de citometría de imagen estandarizado bajo normas ISO 13366-2; IDF 148-2:2016. Físico químico (composicional), su principio es espectrofotometría media infrarroja bajo norma estándar ISO 9622-IDF 141:2013.

Las pruebas básicas de laboratorio realizadas en la recepción de la leche cruda; CMT (California Mas- titis Test) utilizado para controlar el estado sanitario de las ubres (mastitis), la prueba de alcohol para controlar la termo estabilidad proteica ésta se manifiesta mezclando la leche con igual volumen de Etanol a $71 \%$ en peso y/o $78 \%$ en volumen (NTE INEN 9 , 2015), ya que el alcohol a esa concentración produce floculación o coagulación del producto cuando la acidez es igual o superior a $22,5 \mathrm{ml} \mathrm{NaOH}$ 0,1 N/100 ml, una prueba de alcohol positiva indica poca estabilidad de la leche al calor, lo cual es muy importante si la leche tiene fines de pasteurización; la prueba azul de metileno (reductasa) utilizada para estimar cuantitativamente la calidad higiénica de la leche mediante el principio de potencial de óxido -reducción (Eh), la leche cruda contiene $+0,35$ a $+0,40$ voltios (350 a 450 mili-voltios), el cual se debe principalmente al contenido de oxígeno disuelto en el producto. Si por cualquier causa ese oxígeno es separado, el Eh disminuye, esto ocurre cuando los microorganismos crecen en la leche y consumen el oxígeno, si el número de microorganismo es muy elevado, el consumo de oxígeno será mayor y por consiguiente el Eh descenderá rápidamente; si por el contrario, el número de microorganismos es pequeño, el Eh disminuirá lentamente (Universidad de Zulia, 2003); crioscopia estima la adición de agua según la norma (NTE INEN 9, 2015) de $-0,512{ }^{\circ} \mathrm{C}$ a $-0,536{ }^{\circ} \mathrm{C}$ es el rango de una leche cruda normal y lacto fermentación otra prueba utilizada para referirse a la calidad higiénica de tipo lacto fermentables como los coliformes y proteolíticas (Universidad de Zulia, 2003).

\section{Resultados y Discusión}

\subsection{Calidad higiénica}

La Tabla 1, testifica los resultados obtenidos en el monitoreo de la calidad higiénica de la leche cruda en la primera fase, obteniendo el $37.0 \%$ de pequeños y medianos productores con CBT $>600.000 / \mathrm{ml}$, este resultado indica que 233 ganaderos aun maneja el producto en condiciones antihigiénicas en su sistema de ordeño y transporte. El ordeño es un factor determinante en la calidad de la leche, un estudio realizado por (Ramírez Vásquez et al., 2011), a 130 productores revela que 41 (32\%) no realizó el lavado de manos antes del ordeño y 58 $(45 \%)$ no realiza el lavado de ubres, razón por la cual presentaron conteos bacterianos elevados restándole calidad al producto. Es evidente que estas 
condiciones deficientes de manejo están sucediendo con los productores en la provincia, sus resultados confirman estas anomalías, sin embargo, la capacitación constante puede concienciar a los productores y cambiar estas realidades. En el segundo análisis se obtiene $30.7 \%$ de ganaderos con conteos mayores a $600.000 \mathrm{IBC} / \mathrm{ml}$, observando una reducción del $6.3 \%$, se puede aducir que la intervención técnica surgió efecto, sin embargo, no es el esperado, el personal técnico y la coordinación provincial tendrá que plantear nuevas estrategias de intervención y concientización a los pequeños y medianos productores para seguir avanzando en el desarrollo de las buenas prácticas pecuarias en esta provincia fronteriza. Chuquín Yépez, Aquino Ruíz y De la Cruz González (2016) resume en el primer diagnóstico realizado en la provincia que el $57 \%$ fue considerado como leche aceptable para el expendio en la provincia, hoy en día el $70 \%$ se considera leche comercializable según los resultados obtenidos.

Para avanzar en la calidad higiénica de la leche es necesario mantener un nivel tecnológico en la rutina de ordeño, empezando por una buena rutina de limpieza de las vacas lecheras, teniendo presente que los animales sucios presentan mayor riesgo de sufrir patología de la ubre, el correcto manejo es esencial (Bonifaz y Conlago, 2016). Manejar la higiene ambiental es primordial en la tecnología productora de leche, como las medidas elementales de higiene del ordeñador, manteniendo su ropa limpia, uñas recortadas, no padecer de enfermedades, la higiene de las manos factor determinante en la contaminación. Buxadé Carbó (2002), afirma que el 50\% de los operadores se contamina antes de empezar la rutina de ordeño. Otro de los principales factores de la higiene ambiental a considerar es la calidad de agua, en las zonas rurales se debe considerar critica por el deficiente tratamiento de las aguas tanto para consumo como para el laboreo del ordeño (González, Monila y Coca, 2010). Todos los factores antemencionados y otros determinan la calidad higiénica de la leche en una finca. Los productores de la provincia deben trabajar a fondo en estos temas, si el objetivo es mantenerse en el mercado y empezar a competir como proveedores de leche de calidad integral.

\subsection{Calidad sanitaria}

De 630 productores en la provincia el 33.3\% (210) de ellos resultaron con conteo de Células Somáticas $>500.000 / \mathrm{ml}$ evidenciando que mantienen problemas sanitarios por la delicada salud de la glándula mamaria que están presentando, es decir hay presencia de mastitis subclínica y clínica; un $16.8 \%$ (106) de productores presentan en la primera fase altos conteos de CS $/ \mathrm{ml}$ y CBT $/ \mathrm{ml}$ revelando problemas higiénico y sanitario en la leche expendida para la industria. Los datos obtenidos en la fase dos comparados con los datos de la fase uno muestra que el conteo de células somáticas $>500.000 / \mathrm{ml}$, no existió una diferencia positiva de mejora más bien existió un aumento del $1 \%$, esto confirma que se mantuvo los problemas sanitarios en las vacas de los ganaderos en la provincia durante la intervención técnica. Chuquín et al. (2017), revela en el primer diagnóstico realiza en la provincia que apenas el $21.4 \%$ de los ganaderos detecta y realizan el control de la mastitis, actualmente se continua evidenciando este problema grave en el control sanitario, el mismo autor también describe que a nivel provincial apenas el $52.7 \%$ cumple con el criterio de tratamiento preventivo de la mastitis al momento del secado, esto puede explicar el por qué la calidad sanitaria continúa siendo un problema en la provincia, agregándole a esto que menos del $50 \%$ de ganaderos utiliza mano de obra profesional para el tratamiento sanitario, esto puede repercutir en más problemas incontrolables en las vacas lecheras en un futuro. Con respecto al primer diagnósticos realizado en la provincia, Chuquín et al. (2017), resalta que el $65 \%$ de la leche expendida en la provincia es de calidad sanitaria aceptable, actualmente el $67 \%$ se consideraría con conteo celular menor a 500.000 $\mathrm{cs} / \mathrm{ml}$.

\subsubsection{Calidad sanitaria de los hatos lecheros}

El seguimiento realizado al $33.3 \%$ de los productores con conteo de células somáticas mayor a $500.000 / \mathrm{ml}$, se les realizó el diagnóstico a un total de 1094 vacas productoras, obteniendo los siguientes resultados, como indica en la Tabla 2. 
Tabla 1. Conteo celular y bacteriano de pequeños y medianos productores asociados, de los 5 cantones de la provincia del Carchi.

\begin{tabular}{|c|c|c|c|c|c|c|c|c|c|c|}
\hline \multirow[t]{2}{*}{ Asociaciones } & \multicolumn{2}{|c|}{$\begin{array}{c}\text { Total } \\
\text { muestras }\end{array}$} & \multicolumn{4}{|c|}{ CCS $>500.000$} & \multicolumn{4}{|c|}{ CBT $>600.000$} \\
\hline & TM 1 & TM 2 & Toma 1 & $\%$ & Toma 2 & $\%$ & Toma 1 & $\%$ & Toma 2 & $\%$ \\
\hline Linea roja & 112 & 87 & 43 & 38.4 & 37 & 42.5 & 10 & 8.9 & 13 & 14.9 \\
\hline 20 de marzo & 13 & 10 & 5 & 38.5 & 5 & 50.0 & 2 & 15.4 & 3 & 30.0 \\
\hline Tuquer & 23 & 13 & 5 & 21.7 & 3 & 23.1 & 4 & 17.4 & 4 & 30.8 \\
\hline Pizan & 25 & 13 & 6 & 24.0 & 1 & 7.7 & 10 & 40.0 & 3 & 23.1 \\
\hline Progresista mirador & 29 & 29 & 8 & 27.6 & 7 & 24.1 & 6 & 20.7 & 5 & 17.2 \\
\hline Taya & 30 & 23 & 4 & 13.3 & 5 & 21.7 & 5 & 16.7 & 3 & 13.0 \\
\hline Avancemos juntos & 15 & 13 & 4 & 26.7 & 3 & 23.1 & 7 & 46.7 & 4 & 30.8 \\
\hline Incca promsa & 24 & 20 & 8 & 33.3 & 5 & 25.0 & 9 & 37.5 & 10 & 50.0 \\
\hline Mariscal sucre & 27 & 18 & 11 & 40.7 & 9 & 50.0 & 19 & 70.4 & 14 & 77.8 \\
\hline Chitán & 38 & 31 & 12 & 31.6 & 17 & 54.8 & 19 & 50.0 & 21 & 67.7 \\
\hline Centro agricola tulcán & 18 & 12 & 6 & 33.3 & 7 & 58.3 & 11 & 61.1 & 6 & 50.0 \\
\hline Bicundos & 42 & 16 & 15 & 35.7 & 3 & 18.8 & 26 & 61.9 & 8 & 50.0 \\
\hline Palo blanco & 10 & 9 & 3 & 30.0 & 2 & 22.2 & 3 & 30.0 & 1 & 11.1 \\
\hline Emprendedores & 18 & 15 & 7 & 38.9 & 3 & 20.0 & 8 & 44.4 & 3 & 20.0 \\
\hline San pedro & 52 & 41 & 24 & 46.2 & 16 & 39.0 & 14 & 26.9 & 11 & 26.8 \\
\hline Sendero campo fertil & 22 & 19 & 9 & 40.9 & 7 & 36.8 & 15 & 68.2 & 3 & 15.8 \\
\hline Delicia & 95 & 58 & 29 & 30.5 & 17 & 29.3 & 47 & 49.5 & 18 & 31.0 \\
\hline Q'señor & 20 & 12 & 5 & 25.0 & 4 & 33.3 & 10 & 50.0 & 8 & 66.7 \\
\hline Agroincas & 17 & 10 & 6 & 35.3 & 3 & 30.0 & 8 & 47.1 & 0 & 0.0 \\
\hline TOTAL & 630 & 449 & 210 & 33.3 & 154 & 34.3 & 233 & 37.0 & 138 & 30.7 \\
\hline
\end{tabular}

$\mathrm{CCS}=$ Conteo de Células Somáticas

$\mathrm{CBT}=$ Conteo Bacteriano Total

$\mathrm{TM}=$ Toma de Muestras

Tabla 2. Prueba CMT realizada a 1094 vacas lecheras de 210 productores de los 5 cantones de la provincia del Carchi.

\begin{tabular}{cc}
\hline Prueba CMT & $\begin{array}{c}\text { Resultado en \% } \\
\text { (pezones afectados) }\end{array}$ \\
\hline - (Negativo) & 60.09 \\
T (trazas) & 15.05 \\
+ (Positiva nivel 1) & 15.88 \\
++ (Positiva nivel 2) & 7.07 \\
$+++($ Positiva nivel 3) & 0.8 \\
Pezones perdidos & 1.12 \\
Total: & $\mathbf{1 0 0 \%}$ \\
\hline
\end{tabular}


El 39.9\%, es decir más de un tercio de las vacas en producción de los ganaderos de la provincia presentan problemas serios en el control de la mastitis bovina, este problema posiblemente sea el efecto del descuido del pequeño y mediano productor en las buenas prácticas de ordeño (Bonifaz y Requelme, 2011), como también lo señala (Ramírez Vásquez et al., 2011) que el $90 \%$ de la mastitis es producida por deficiencias en el ordeño, lo que significa que esta enfermedad se produce en condiciones favorables que el mismo productor les proporciona, tales como: mal ordeño, falta de higiene al momento del ordeño, falta de higiene del área del ordeño, no separar los animales afectados de los sanos, no dar el tratamiento adecuado ni la dosis correcta y necesarias a cada animal enfermo (Buxadé Carbó, 2002). Por esta razón la mastitis subclínica sigue siendo la enfermedad silenciosa más costosa en la provincia por la pérdida de producción, la baja calidad del producto y consecuentemente problemas en la industrialización, esto conlleva una pérdida económica severa para el productor (Mellado Bosque, 2010; Bonifaz y Conlago, 2016), por esta razón es importante monitorea la enfermedad en los animales y la calidad de la leche en la recepción para luego ser expendida para la industria láctea.

\subsubsection{Calidad sanitaria por proveedor mediante CMT}

La prueba CMT realizada a cada proveedor en la recepción de las asociaciones y centros de acopio arrojó los siguientes resultados del Tabla 3.

En la Tabla 3, se aprecia los resultados de las dos fases donde aparentemente hay una mejora del $13.16 \%$ de productores detectados negativamente ante la prueba CMT, demostrando que este tipo de pruebas rápidas son herramientas importantes en un laboratorio básico de control de la calidad en un centro de recepción de leche cruda.

De acuerdo a los datos obtenidos, la leche cruda de pequeños y medianos productores asociados en ésta provincia mejora un $13.16 \%$ comparados con los resultados de la primera fase, estos resultados motiva a seguir buscando modelos de desarrollo en la concientización del control del a enfermedad (mastitis) para lograr conseguir leche de productores de pequeña escala de calidad sanitaria.

Tabla 3. Prueba CMT realizada en la recepción de leche a los productores de los 5 cantones de la provincia del Carchi.

\begin{tabular}{cccc}
\hline Prueba CMT & $\begin{array}{c}\text { Porcentaje (\%) } \\
\text { de productores } \\
\text { Primera Toma }\end{array}$ & $\begin{array}{c}\text { Porcentaje (\%) } \\
\text { de productores } \\
\text { Segunda Toma }\end{array}$ & Diferencia \\
\hline - (Negativo) & 35.41 & 48.61 & 13.16 \\
T (trazas) & 37.01 & 31.02 & -5.99 \\
+ (Positiva nivel 1) & 19.59 & 15.51 & -4.08 \\
++ (Positiva nivel 2) & 6.97 & 3.94 & -3.03 \\
$+++($ Positiva nivel 3) & 1.02 & 0.93 & -0.09 \\
Total positivo & 64.59 & 51.39 & -13.2 \\
Total: & $\mathbf{1 0 0} \%$ & $\mathbf{1 0 0} \%$ & \\
\hline
\end{tabular}

3.3 Calidad físico químico de la leche cruda

\subsubsection{Composición química}

Los resultados de la Tabla 4 , indican que el $7.47 \%$ y $8.12 \%$ de pequeños y medianos productores de leche tienen problemas en cuanto al porcentaje de grasa y proteína respectivamente, reflejando posibles problemas de adulteración con agua o deficiente nutrición de las vacas lecheras. En lo respecta a la nutrición, después de los factores genéticos los no genéticos como la alimentación es el factor determinante en la producción de grasa y proteína en la leche. El clima de la región también juega un papel crucial en el manejo alimenticio de la vaca, como las épocas de lluvia se debe tener en cuenta la disponibilidad y digestibilidad de los potreros especialmente en el racionamiento de proteína, mientras que en épocas secas las altas temperaturas y el aumento de fibra de los pastizales puede afectar la 
calidad de la ración diaria suministrada, afectando la producción de los sólidos totales en la leche, Valdés y Canto (2015) sostienen que el aporte de fibra en la ración alimenticia por ejemplo la grasa puede subir hasta en un $1 \%$ y la proteína en $0.3 \%$, también acotan que la alimentación incide directamente en la producción de grasa, mientras que la proteína depende del factor genético, pero que la alimentación define el techo efectivo en ambos casos. La norma NTE INEN 9 (2015), establece que una leche cruda debe contener un mínimo de 3\% grasa y $2.9 \%$ de proteína, por lo que aún no se cumple en su totalidad en la provincia.

La tabla de pago por calidad emitida en septiembre del 2013 por el MAGAP, establece que el costo de sustentación del litro de leche cruda es de 42 cen- tavos de dólar, con el contenido de grasa de 3.0\% y proteína en $2.9 \%$. Con este argumento la leche de la provincia el $92.5 \%$ y $91.9 \%$ de grasa y proteína respectivamente su leche cruda tiene derecho al pago por calidad, sin embargo, este precio puede descender o ascender por el contenido bacteriano, que la tabla estipula que debe contener $\leq 300.000 \mathrm{IBC} / \mathrm{ml}$ o $300.000 \mathrm{ufc} / \mathrm{ml}$ para obtener las respectivas bonificaciones, caso contrario se penaliza bajando su costo inclusive de sustentación.

Con respecto al primer diagnóstico la grasa y proteína se mantenía en 90 y $86 \%$ respectivamente, actualmente se puede mencionar que hay una mejora de 2.5 y $6 \%$ respectivamente, manteniéndose la calidad composicional (Chuquín et al., 2017).

Tabla 4. Porcentaje de grasa y proteína en la leche cruda de los productores de los 5 cantones de la provincia del Carchi.

\begin{tabular}{cccccc}
\hline \multirow{2}{*}{ Asociaciones } & \multicolumn{3}{c}{ Grasa } & \multicolumn{2}{c}{ Proteína } \\
& $\mathbf{N}^{\circ}$ prov & $<\mathbf{3}$ & $\mathbf{\%}$ & $<\mathbf{2 . 9}$ & $\mathbf{\%}$ \\
\hline Agroincas & 42 & 6 & 14.29 & 2 & 4.76 \\
San francisco/línea roja & 27 & 3 & 11.11 & 7 & 25.93 \\
A. Bicundos & 29 & 5 & 17.24 & 4 & 13.79 \\
A. Emprendedores & 22 & - & - & 1 & 4.55 \\
A. San pedro & 9 & 2 & 22.22 & 2 & 22.22 \\
Centro agrícola tulcán & 8 & - & - & 1 & 12.5 \\
Chitán & 8 & 2 & 25 & - & - \\
La paz & 48 & 8 & 16,67 & 7 & 14.58 \\
Mariscal sucre & 47 & 3 & 6.38 & 2 & 4.26 \\
Piartal & 10 & 1 & 10 & 1 & 10 \\
Pizán & 24 & 2 & 8.33 & 2 & 8.33 \\
Comercializadora/taya & 30 & 4 & 13.33 & 5 & 16.67 \\
Tuquer & 13 & 3 & 23.08 & 1 & 7.69 \\
Progresista mirador & 18 & 1 & 5.56 & 2 & 11.11 \\
Q'señor & 52 & 6 & 11.54 & 13 & 25 \\
Total: & $\mathbf{6 1 6}$ & $\mathbf{4 6}$ & $\mathbf{7 . 4 7}$ & $\mathbf{5 0}$ & $\mathbf{8 . 1 2}$ \\
\hline
\end{tabular}

\subsubsection{Reacción de estabilidad proteica (Prueba de alcohol)}

Los resultados de la Tabla 5, tienen relación directa con los altos conteos bacterianos, esto implica que estas leches crudas dieron positivo a la prueba de alcohol, confirmando la deficiente calidad higiénica. Los porcentajes $13.93 \%$ y $13.19 \%$ en las dos fases analizadas respectivamente corrobora la falta de calidad de la leche que se deposita en los centros de recolección en la provincia. 
Tabla 5. Resumen de la prueba de alcohol realizado a los productores de los 5 cantones de la provincia del Carchi.

\begin{tabular}{cccc}
\hline Resultado & $\begin{array}{c}\text { Primera toma } \\
\text { de muestras }\end{array}$ & $\begin{array}{c}\text { Segunda toma } \\
\text { de muestras }\end{array}$ & Diferencia \\
\hline Negativos & 86.07 & 86.81 & -0.75 \\
Positivos & 13.93 & 13.19 & 0.74 \\
\hline
\end{tabular}

La prueba de alcohol debe realizarse todos los días en los centros de recolección de la leche cruda, porque todos los días es una realidad aparte, un descuido en el sistema y los resultados son insatisfactorios en la calidad del producto, es la única forma de controlar el cumplimiento o incumplimiento de las mínimas normas de higiene en el proceso. Es la única prueba empírica, rápida que puede ayudar a juzgar el producto al momento de la recepción.

\subsubsection{Crioscopía}

Los resultados de crioscopía muestran que el $16.43 \%$ de productores incluidos en este estudio aparentemente adulteran la leche con agua, pero antes de juzgar mediante esta prueba se sugiere realizar un seguimiento en el hato lechero para identificar de cerca el problema de aguado u otros como deficiencia nutricional, época de lactancia, temperatura ambiental, patologías fisiológicas que pueden estar atravesando los animales (González Cuascota, 2013), y consecuentemente la crioscopia este fuera de las normas estatales.

Chuquín Yépez, Aquino Ruíz y De la Cruz González (2016), revela que el 70\% de ganaderos superaba los requisitos de la norma (NTE INEN 9, 2015), en el primer diagnóstico realizado en la provincia, actualmente se puede apreciar un $13.57 \%$ de avance en el control de adulteración con agua.

\subsubsection{Tiempo de reducción de azul de metileno (Prueba de reductasa)}

El promedio de los porcentajes de los ganaderos de los 5 cantones de la provincia respondió al tra- tamiento, hay un avance significativo luego de la intervención técnica. Sin embargo, este avance no es satisfactorio o esperado, en la primera fase el $70.64 \%$ (308) de los productores obtienen una leche de calidad comprobada mediante este examen al momento de la recepción, mientras que en la segunda fase el $81.29 \%$ (352) de los productores proporcionan leche de calidad según esta prueba.

La prueba de reductasa en la cualificación de la calidad higiénica de la leche cruda, indica a groso modo el grado de contaminación bacteriana. En la Tabla 6. Se observa que los promedios en las dos tomas de muestras antes y después de la intervención técnica, hay un incremento del $10.65 \%$ de los promedios >a 5 horas que según la norma NTE INEN 9 (2015), el producto es de calidad.

En un estudio realizado por Buñay y Peralta (2015), en 168 muestras de proveedores de leche cruda en la provincia del Cañar, escasamente el $32.1 \%$ cumple el criterio de calidad impuesta por la NTE INEN 9 (2015) >a 3 horas lo que evidencia que en la provincia del Carchi el avance es significativo en el control de la calidad de la materia prima, pero aún se necesita seguir trabajando.

Esta prueba mantiene un proceso cuidadoso, pero con capacitación es manejable para controlar el estado higiénico de la leche, los centros de recolección deben mantenerla para el control diario y vigilar la calidad del producto recibido (Zambrano y Grass, 2008) y poder tomar las medidas pertinentes con los usuarios asociados y poder avanzar en el proceso de calidad. 
Tabla 6. Resumen de la prueba de reductasa realizado a los productores de los 5 cantones de la provincia del Carchi.

\begin{tabular}{ccccccc}
\hline Asociaciones & \multicolumn{2}{c}{$\begin{array}{c}\text { \%horas } \\
\text { \% primera Toma }\end{array}$} & $\begin{array}{c}3-5 \text { horas } \\
\text { primoras }\end{array}$ & $\begin{array}{c}<3 \text { horas } \\
\text { \% segunda Toma }\end{array}$ & $\begin{array}{c}3-5 \text { horas } \\
\text { sem horas }\end{array}$ \\
\hline 20 de marzo & 7.69 & 23.08 & 69.23 & 0 & 0 & 100 \\
Agroincas & 33.33 & 47.62 & 19.05 & 0 & 14.29 & 85.71 \\
A. Juntos & 29.41 & 23.53 & 47.06 & 23.53 & 23.53 & 52.94 \\
Bicundos ii & 20.45 & 22.73 & 56.82 & 4.55 & 0 & 95.45 \\
Emprendedores & 0 & 0 & 100 & 7.69 & 19.23 & 73.08 \\
La delicia & 12.36 & 21.35 & 66.29 & 11.11 & 11.11 & 77.78 \\
Mariscal sucre & 25.93 & 25.93 & 48.15 & 44 & 0 & 56 \\
Dolorosa & 20 & 10 & 70 & 30 & 20 & 50 \\
Pizán & 7.69 & 15.38 & 76.92 & 4.35 & 4.35 & 91.3 \\
Progresista m. & 3.7 & 0 & 96.3 & 6.06 & 12.12 & 81.82 \\
Q'señor & 60 & 10 & 30 & 5 & 20 & 75 \\
S. C. Fértil & 0 & 9.52 & 90.48 & 0 & 9.52 & 90.48 \\
San pedro & 0 & 4.65 & 95.35 & 2.27 & 2.27 & 95.45 \\
Solferino & 12.5 & 4.17 & 83.33 & 0 & 12.5 & 87.5 \\
Tuquer & 0 & 11.11 & 88.89 & 0 & 16.67 & 83.33 \\
\hline
\end{tabular}

\subsubsection{Lacto fermentación}

El $48.2 \%$ y $6.57 \%$ de productores de la provincia mantienen problemas de bacteria de tipo fermentables (coliformes) y proteolíticas respectivamente, el $44.91 \%$ de productores presento leche negativa a la prueba reflejando un producto higiénico de buena calidad, y se obtuvo $0.31 \%$ de las muestras que no presento coagulación presuntamente por contener sustancias químicas, detergentes, pesticidas desde los establos. Las leches con resultados negativos son favorables para la industria láctea productora de quesos (Figura 1). Esta prueba ayudó a identifica que la leche de la provincia tiene serias deficiencias en la calidad higiénica originada en los establos.

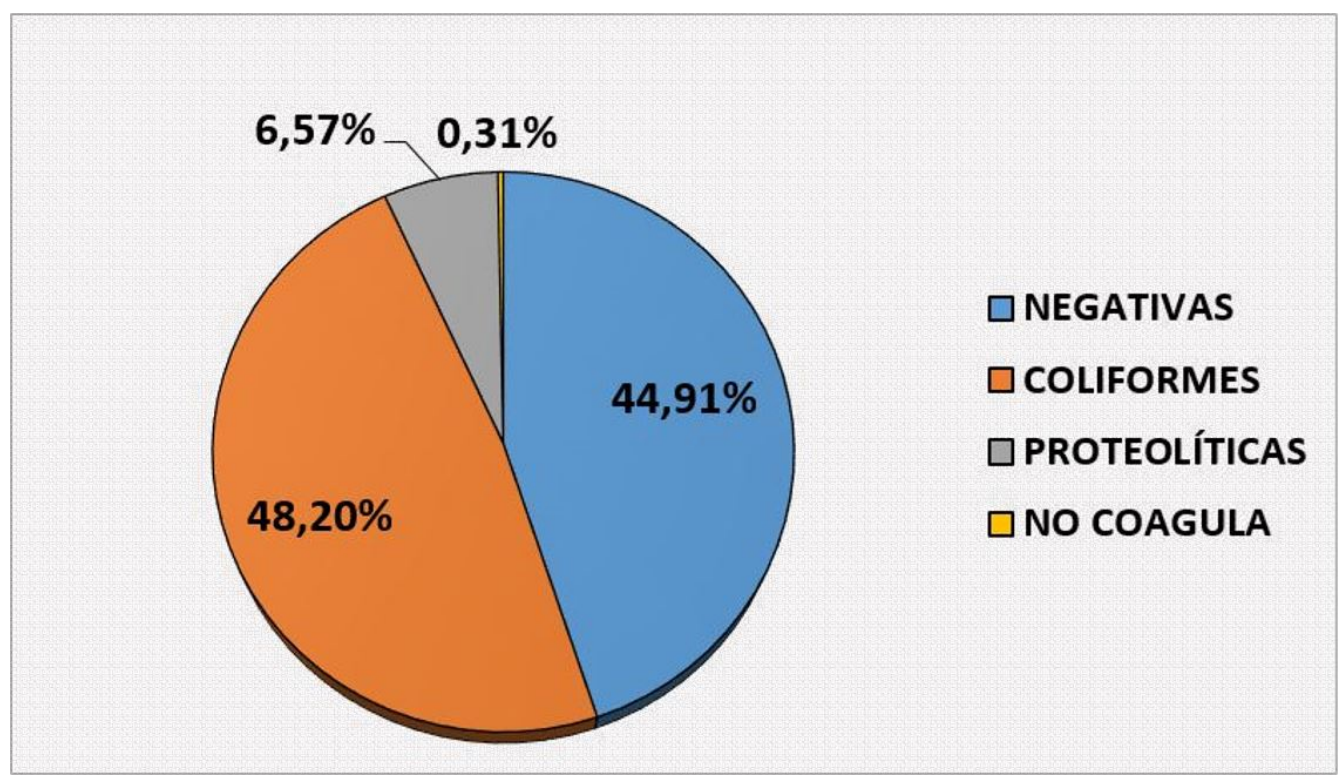

Figura 1. Resultado general de la prueba de lacto fermentación de los pequeños y medianos productores de los 5 cantones de la provincia del Carchi. 


\section{Conclusiones}

Los análisis de laboratorio sin duda siguen siendo una herramienta fundamental para el diagnóstico de la calidad de la leche cruda a nivel de productor. Las pruebas cualitativas como el CMT ayuda a diagnosticar problemas sanitarios a nivel de productor; mientras que la prueba de alcohol, reductasa, lacto fermentación ayudaron a determinar el estado higiénico a groso modo de la leche cruda. Las pruebas cuantitativas como el CBT, CCS, Crioscopia, son pruebas indicativas de problemas evidentes y comprobados de problemas higiénicos, sanitarios y de adulteración del producto.

Un tercio de la población de los ganaderos de la provincia $(33.3 \%)$ continúan con serias deficiencias en el diagnóstico y control de la mastitis bovina. Se evidenció que los conteos celulares superiores a $500.000 \mathrm{cs} / \mathrm{ml}$ del bidón de los productores, el $40 \%$ de ellos mantienen animales positivos a la prueba CMT en producción, lo que significa que aún hay deficiencia en el diagnóstico realizado por el ganadero a sus vacas, dificultando aún más la prevención y tratamiento de la enfermedad. La calidad higiénica continúa siendo el tópico de todos los involucrados en la cadena de valor de la leche cruda. Sin duda los resultados de laboratorio son el reflejo del manejo integral de los animales en producción y mejorar dependerá del esfuerzo y sabiduría única del ganadero. La calidad físico química como la grasa y proteína, cumplen más del $90 \%$ de los ganaderos, manteniéndose en los límites establecidos por las normas estatales. Un correcto manejo en el suministro alimenticio puede ayudar a obtener mejores resultado de grasa y proteína.

\section{Agradecimiento}

De manera especial a los productores de la provincial del Carchi, al personal técnico de GADPC; fundación alpina y UPS por el apoyo y la entrega al proyecto de investigación, por todos los recursos destinados.

\section{Referencias}

Bacilio, V. 2016. Evaluación de transferencia de tecnología en unidades de producción de leche en pequeña escala, en el municipio de Aculco, estado de México. In Tesis de Grado. Universidad Au- tónoma del Estado de México. Disponible en: https: //goo.gl/PyTFvq.

Bonifaz, N y F. Conlago. 2016. "Prevalencia e incidencia de mastitis bovina mediante la prueba de California Mastitis Test con identificación del agente etiológico, en Paquiestancia, Ecuador." La Granja: Revista de Ciencias de la Vida 24(2):43-52. doi: http:/ /dx.doi.org/10.17163/lgr.n24.2016.04.

Bonifaz, N y N. Requelme. 2011. "Buenas prácticas de Ordeño y la Calidad higiénica de la Leche en el Ecuador." La Granja: Revista de Ciencias de la Vida 14(2):43-52. doi: http:/ /dx.doi.org/10.17163/lgr. n14.2011.04.

Buñay, N y F. Peralta. 2015. Determinación del recuento de aerobios mesófilos en leche cruda que ingresa a industrias lacto Ochoa - Fernández CIA. Ltda. Tesis de grado, Universidad de Cuenca, Ecuador. Disponible en: https://goo.gl/NwBQ3F.

Buxadé Carbó, C. 2002. El ordeño en el ganado vacuno: aspectos claves. Ediciones Mundi-Prensa. Disponible en: https://goo.gl/VcK1Sa.

CANILEC. 2011. El libro blanco de la leche y productos lácteos. CANILEC. Disponible en: https: //goo.gl/4HFofL.

Chuquín, H, E Ibarra, E De la Cruz y P. Simbaña. 2017. "Diagnóstico de cumplimiento de las buenas prácticas pecuarias en la provincia del Carchi." Revista Visión Empresarial (6):206-2017.

Chuquín Yépez, H. G, E. L Aquino Ruíz y E. G. De la Cruz González. 2016. “Diagnóstico del manejo de la calidad de leche y del queso en la provincia del Carchi." Revista Sathiri 11(11):153-168. Disponible en: https://goo.gl/FY76kd.

FAO. 2017. "Calidad y evaluación." Organización de las Naciones Unidas para la Agricultura y la Alimentación. Disponible en: https://goo.gl/ Fg7nV8.

GADPC. 2016. "Gobierno Autónomo Descentralizado de la Provincia del Carchi.".

González Cuascota, M. V. 2013. Estudio del punto crioscópico de leche cruda bovina, en dos pisos altitudinales y dos épocas del año. In Tesis de Grado, Universidad Politécnica Salesiana, Ecuador. Disponible en: https://goo.gl/xANWDZ. 
González, G, B Monila y R. Coca. 2010. Calidad de la leche cruda. In Primer Foro sobre Ganadería Lechera de la Zona Alta de Veracruz. Disponible en: https://goo.gl/KvJU83.

MAGAP. 2013. “Acuerdo 394: Regúlese y contrólese el precio del litro de leche cruda pagada en finca y/o centro de acopio al productor y promuévase la calidad e inocuidad de la leche cruda.".

Mellado Bosque, M. 2010. Producción de leche en zonas templadas y tropicales. Editorial Trillas. Disponible en: https: / /goo.gl/2XRHWp.

NTE INEN 9. 2015. "Leche cruda. Requisitos. Sexta revisión." Instituto Ecuatoriano de Normalización. Disponible en: https://goo.gl/7fAkQE.

NTE INEN-ISO 707. 2014. “Leche y productos lácteos. Directrices para la toma de muestras (ISO 707:2008, IDT)." Instituto Ecuatoriano de Normalización. Disponible en: https:/ /goo.gl/7cGKi5.

Ramírez Vásquez, N, O Arroyave Henao, M CerónMuñoz, M Jaramillo, J Cerón y L. G. Palacio. 2011. "Factores asociados a mastitis en vacas de la microcuenca lechera del altiplano norte de Antio- quia, Colombia." Revista de Medicina Veterinaria (22):31-42. [en línea] disponible en: https:/ /goo. gl/QMZoyv.

Universidad de Zulia. 2003. Introducción al control de calidad de la leche cruda, Guía práctica. In Cátedra de Ciencia y tecnología de la Leche. Disponible en: https://goo.gl/EjkpEK.

Valdés, C y F. Canto. 2015. Alimentación de Vacas Lecheras en Pastoreo y sus Efectos en el Contenido de Sólidos Lácteos. INIA. Disponible en: https: //goo.gl/aLVMGm.

Villegas de Gante, A y A. Santos Moreno. 2011. Manual básico para elaborar productos lácteos. Trillas Sa de Cv. Disponible en: https://goo.gl/nNCfTY.

Zambrano, J y J. Grass. 2008. “Valoración de la calidad higiénica de la leche cruda en la asociación de productores de leche de Sotará - asproleso, mediante las pruebas indirectas de resazurina y azul de metileno." Biotecnología en el Sector Agropecuario y Agroindustrial 6(2):56-66. Disponible en: https://goo.gl/n1yruK. 